\title{
The Immunomodulatory Functions of Butyrate
}

\author{
Mohamed Tausif Siddiqui (D) ${ }^{1,2}$ \\ Gail AM Cresci (iD) 1,3 \\ 'Department of Gastroenterology, \\ Hepatology and Human Nutrition, \\ Digestive Disease and Surgery Institute, \\ Cleveland Clinic, Cleveland, OH, 44I95, \\ USA; ${ }^{2}$ Department of Inflammation and \\ Immunity, Lerner Research Institute, \\ Cleveland Clinic, Cleveland, OH, 44195, \\ USA; ${ }^{3}$ Department of Pediatric \\ Gastroenterology, Cleveland Clinic, \\ Cleveland, $\mathrm{OH}, 44195$, USA
}

\begin{abstract}
The gastrointestinal (GI) system contains many different types of immune cells, making it a key immune organ system in the human body. In the last decade, our knowledge has substantially expanded regarding our understanding of the gut microbiome and its complex interaction with the gut immune system. Short chain fatty acids (SCFA), and specifically butyrate, play an important role in mediating the effects of the gut microbiome on local and systemic immunity. Gut microbial alterations and depletion of luminal butyrate have been well documented in the literature for a number of systemic and GI inflammatory disorders. Although a substantial knowledge gap exists requiring the need for further investigations to determine cause and effect, there is heightened interest in developing immunomodulatory therapies by means of reprogramming of gut microbiome or by supplementing its beneficial metabolites, such as butyrate. In the current review, we discuss the role of endogenous butyrate in the inflammatory response and maintaining immune homeostasis within the intestine. We also present the experimental models and human studies which explore therapeutic potential of butyrate supplementation in inflammatory conditions associated with butyrate depletion.
\end{abstract}

Keywords: butyrate, short chain fatty acids, gut microbiome, gut microbiota, dysbiosis, inflammation, immunity, innate immunity, adaptive immunity, epithelial barrier, inflammatory bowel disease

\section{The Gut Microbiome - Overview}

The human gastrointestinal tract houses trillions of microbes predominantly within the colon known as the gut microbiota (Figure 1). These microbes consist of a commensal blend of bacteria, fungi (mostly yeasts), viruses/phages, archaea, and parasites. ${ }^{1}$ The gut microbiome is a term used to describe the genetic and functional aspects of the gut microbiota. Currently, most knowledge regarding the gut microbiome pertains to its bacterial composition which is reported to be at a $1: 1$ ratio with the body's eukaryotic cellular composition; ${ }^{2}$ and its health is characterized by its richness and diversity. At the phylum level, the gut microbiota is comprised of Bacteroidetes, Firmicutes, Proteobacteria, Actinobacteria, and Verrucomicrobia, with gram negative Bacteroidetes and gram positive Firmicutes representing roughly $90 \%$ of the gut microbiota in healthy humans. ${ }^{1}$ However, with high interpersonal and intrapersonal variability in the human gut microbiota there is no standard microbial ecology that all healthy people share. ${ }^{3}$

While gut colonization begins in utero, the first major colonization occurs and varies with the mode of infant delivery, vaginal versus Cesarean section, and the method of infant feeding, breast milk versus infant formula. ${ }^{4}$ Within the first $2-3$ years of life, gut microbiome development occurs alongside the physiological and immune maturation of the intestine. As the infant diet progresses to solid foods, a sustained
Correspondence: Gail AM Cresc

Tel + I-2 I6-445-0874

Email crescig@ccf.org 


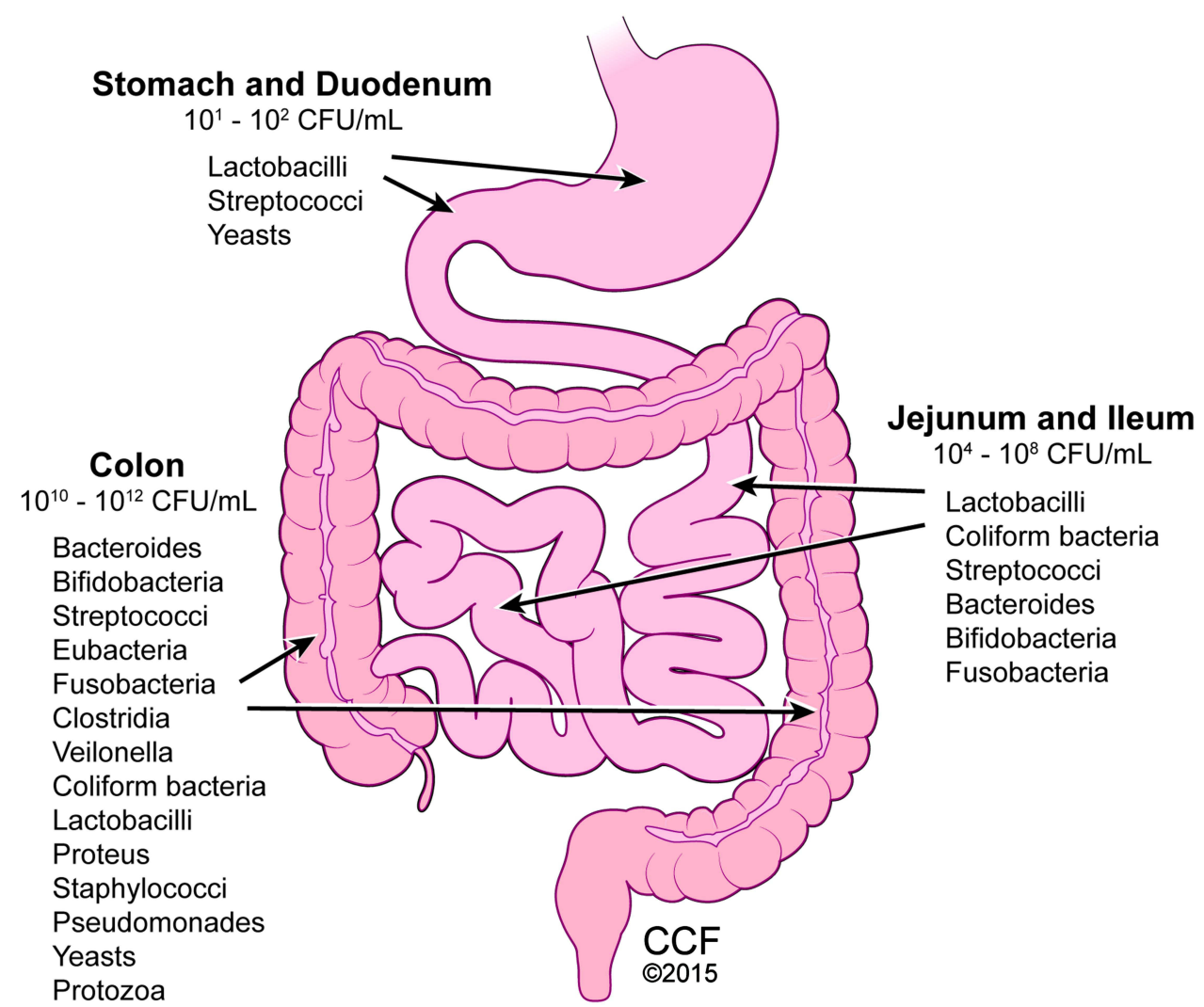

Figure I Distribution of gut microbes within human gastrointestinal tract. Microbiota comprised of bacteria, fungi, yeasts, viruses, and protozoa present throughout the gastrointestinal system, with colon containing the highest number and diversity of microbes. Reprinted with permission, Cleveland Clinic Center for Medical Art \& Photography (C2015. All Rights Reserved. ${ }^{163}$

shift occurs in the richness and diversity of the gut microbiome where it begins to resemble that of an adult. Throughout life, multiple factors can influence the composition of the gut microbiome such as diet, medications, physical, metabolic and psychological stress, geography, and aging which is reviewed elsewhere ${ }^{5}$ (Figure 2).

Diet is one of the main driving factors contributing to the composition and diversity of the gut microbiota. In response to diet, the gut microbiota produces various metabolites. ${ }^{6}$ A diet rich in complex indigestible carbohydrates (eg, fibers) supports gut microbe-derived metabolites such as short chain fatty acids (SCFA), notably acetate, propionate, and butyrate. Conversely, diets low in fiber and high in fat and simple carbohydrates have a low SCFA fermenting capacity and are linked with chronic health conditions such as colorectal cancer and cardio-metabolic diseases. ${ }^{6}$

\section{Crosstalk Gut Microbiota and Host - Mutualism for Homeostasis}

The gut microbiota and its host co-exist in a symbiotic relationship where both parties mutualistically benefit from the presence of the other. The host provides the gut microbiota a safe dwelling niche with a steady supply of nutrients for its survival, and the microbiota supports the host by generating beneficial metabolites, such as vitamins, enzymes and SCFA, participating in pathogen exclusion, and supporting the intestinal epithelial barrier and immune defenses. ${ }^{7}$ The intestinal mucosal immune system is the largest immune constituent in the body that is in contact with the external environment making it essential for host defense and maintaining homeostasis. To accomplish this, the mucosal immune system needs to be tolerant of mutualistic microbes, while at the same time it must ensure a beneficial microbial composition by limiting microbial overgrowth and being reactive to opportunistic pathogens. Studies in germ-free animals indicate the gut microbiome is essential for optimal intestinal immune development and defense. Germ-free animals demonstrate deficiencies in mucosal immune development which compromises their immune defense mechanisms. Absence of a gut microbiome leads to underdeveloped lymphoid structures (eg, Peyer's patches, mesenteric lymph nodes) and 


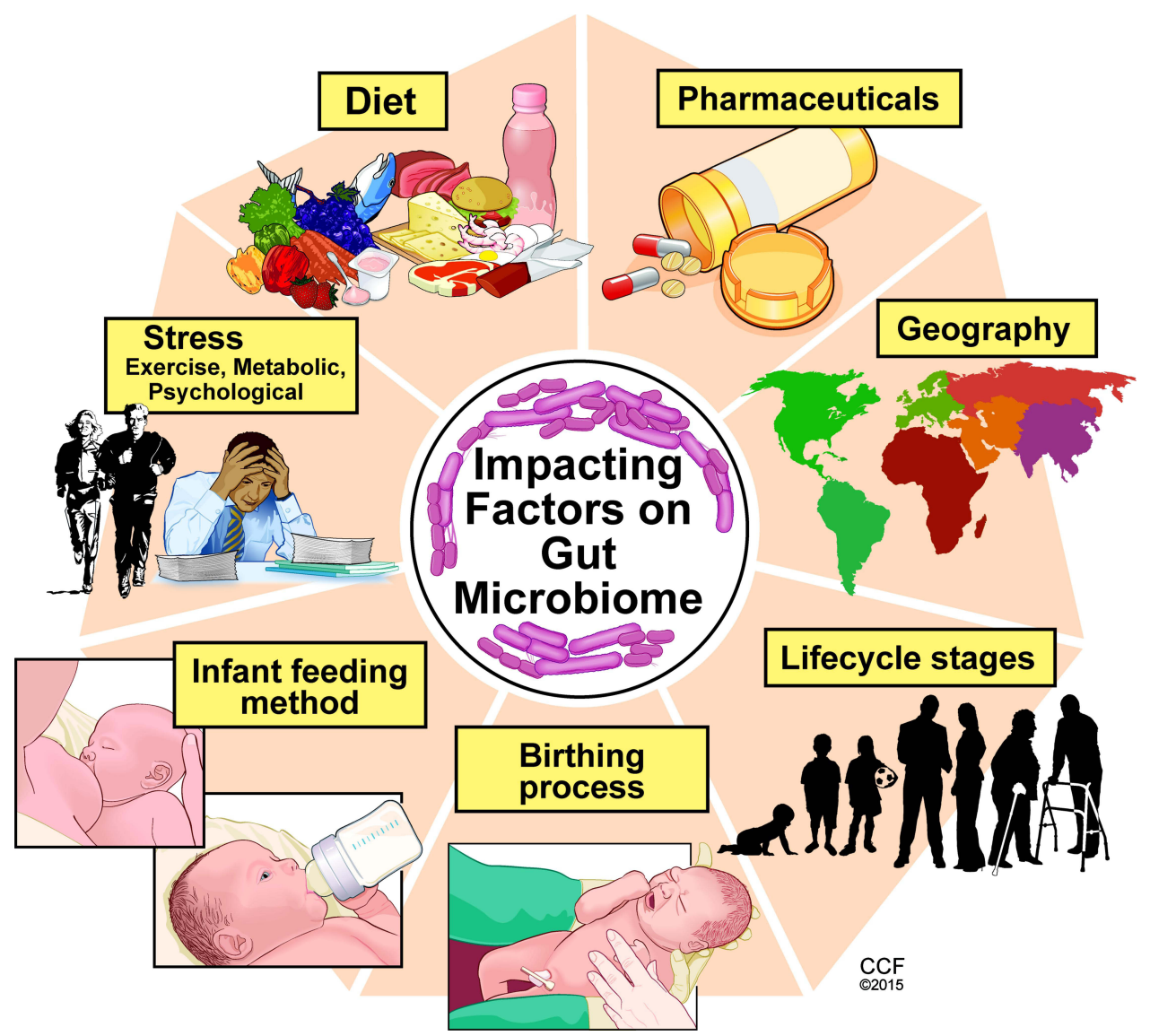

Figure 2 Key factors influencing the composition and diversity of the gut microbiome. Many factors can influence the gut microbiota composition and diversity beginning with the birthing process and first feeding methods. Other factors such as diet, psychological and physiological stress, pharmaceutical exposure, geographic residence and traveling and exposures, are among several factors which influence the microbiome throughout the lifecycle. Reprinted with permission, Cleveland Clinic Center for Medical Art \& Photography @2015. All Rights Reserved. ${ }^{163}$

reduced immune cell populations such as IgA-producing plasma cells, CD4+ lamina propria T-cells and intraepithelial $\alpha \beta$ T-cell receptor CD8+ cells. ${ }^{8,9}$ Angiogenin-4, a Paneth cell-derived antimicrobial peptide important for epithelial host defense against gut microbes, demonstrated decreased gene expression in germ-free compared to conventional mice. ${ }^{10}$ Although the gut microbiome involvement in mucosal immune regulation expands beyond the intestinal tract, ${ }^{9}$ here in this review we focused on intestinal innate and adaptive immunity.

\section{Short-Chain Fatty Acids - Butyrate}

Short-chain fatty acids are organic acids produced predominantly in the colon by gut microbial fermentation of dietary fermentable fiber and resistant starches, and to a lesser extent, dietary and endogenous proteins. ${ }^{11}$ SCFA are monocarboxylates with a concentration ratio in a healthy colonic lumen of roughly 60:25:15 acetate (C2):propionate (C3): butyrate (C4), respectively. ${ }^{11}$ The presence of these weak acids in the colon lowers luminal $\mathrm{pH}$ which favors the growth of butyrate-producing bacteria. The use of metagenomic-targeted approaches have identified butyrateproducing bacteria as a functional group rather than a coherent phylogenic group. ${ }^{12}$ Predominating within the Firmicutes phylum within clostridial clusters IV and XIVa, butyrate producers are gram-positive, strictly anaerobic and oxygen-sensitive, saccharolytic bacteria. ${ }^{11}$ Numbers of clostridial clusters IV and XIVa are low in the neonatal period, slightly increase up to 2 years of age, and then dramatically rise during late childhood and adolescence, but then begin to decline again in adulthood and especially in the elderly. $^{13,14}$

\section{Butyrate}

The SCFA butyrate is known to be of high biological importance. Butyrate is the primary fuel source for the colonocyte where nearly $90 \%$ of generated butyrate is metabolized locally in the colonocyte. SCFA absorption 
occurs by passive diffusion, as well as active transport by intestinal epithelial cells via sodium-coupled monocarboxylate transporter 1 (SMCT1 encoded by SLC5A8) and proton-coupled monocarboxylate transporter 1 (MCT1; encoded by SLC16A1). ${ }^{15}$ Expression of SCFA transporters is regulated by the presence of SCFA, as demonstrated in germ-free mice and conditions of gut dysbiosis and reduced luminal SCFA. ${ }^{16-18}$ SCFA not metabolized in the colon is carried into the liver via the portal vein and used as an energy substrate for hepatocytes, thus leaving very little butyrate in the systemic circulation. ${ }^{19}$ However, SCFA can reach the brain and cross the blood-brain barrier likely due to high expression of MCT1 on endothelial cells, with average butyrate concentrations of $17.0 \mathrm{pmol} /$ $\mathrm{mg}$ of brain tissue in humans. ${ }^{20}$ Butyrate supports the integrity of the intestinal epithelial barrier by regulating the expression of tight junctional proteins and supporting intestinal mucus production. ${ }^{19,21}$ Laboratory studies suggest that butyrate assists with gut motility ${ }^{22}$ by serving as a ligand and activator of SCFA receptors, ${ }^{23}$ inducing the gut hormone peptide $\mathrm{YY}^{24}$ or mediating enterochromaffin cell release of serotonin. ${ }^{25}$ Butyrate enhances water and electrolyte absorption through upregulation of the $\mathrm{Na}^{+}-\mathrm{H}^{+}$ exchanger and induction of genes encoding for ATPase ion exchangers. ${ }^{22}$ As a histone deacetylase inhibitor, butyrate can alter gene expression, inhibit cell proliferation, and induce cell differentiation or apoptosis, leading to butyrate's anti-tumor properties. ${ }^{21}$ Butyrate also has antiinflammatory properties due in part to its role in HDAC inhibition in various cell types such as the intestinal epithelium and immune cells, as well as inhibition of the activation of the transcription factor nuclear factor- $\mathrm{\kappa B}$ $(\mathrm{NF}-\mathrm{\kappa B}){ }^{21}$ Through downregulation of the NF- $\mathrm{kB}$ signaling pathway, butyrate has been shown to modulate proinflammatory cytokine production. ${ }^{21,26}$

\section{SCFA and G-Protein Coupled Receptors}

SCFA can modulate cellular functions by activating SCFAsensing pertussis toxin-sensitive $\mathrm{G}_{i}$-protein coupled receptors (GPCR). These include GPR41 (free fatty acid receptor 3; FFAR3), GPR43 (free fatty acid receptor 2; FFAR2), and GPR109A (hydroxycarboxylic acid receptor 2; HCAR2). These receptors are expressed in several tissue and cell types in humans and animals ${ }^{18,27-35}$ (Table-1).

Through interactions with these GPCRs, SCFA can activate anti-inflammatory signaling cascades and modulate intestinal homeostasis. Using experimental mouse models to induce intestinal inflammation and bacterial infection, GPR43, GPR41, and SCFA exposure were necessary for mounting an immune response, mitigating inflammatory insults, and clearing bacteria ${ }^{36}$ via the induction of chemokine and cytokine release in intestinal epithelial cells and activated effector T cells. These responses were due to activated extracellular signal-regulated kinase $1 / 2$ and p38 mitogen-activated protein kinase which were GPR41/43 dependent. ${ }^{36}$ GPR109A is highly expressed on innate immune cells and adipose tissue, as well as the apical membrane of intestinal epithelial cells. ${ }^{34}$ GPR $109 \mathrm{a}^{-/-}$mice have altered intestinal immune capacity with reduced frequency of Treg and IL-10 producing CD4+ T cells in the colon. ${ }^{33}$ When subjected to chemically-induced colonic inflammation and cancer with dextran sodium sulfate (DSS) and azoxymethane (AOM), GPR109a $\mathrm{a}^{-/-}$mice had exacerbated inflammation and colon carcinogenesis, suggesting the importance of GPR109a in promoting anti-inflammatory properties and colonic homeostasis. ${ }^{33}$ Further studies showed that Gpr109adependent signaling suppressed IL-23 production from dendritic cells and reduced colonic inflammation. ${ }^{37}$ Presence of GPR109a was also shown to protect against experimental Escherichia coli (ETEC) infection, secretory IgA responses, and intestinal barrier integrity. ${ }^{38}$ Sivaprakasam et al provided a detailed review of SCFA receptors. ${ }^{39}$

\section{Intestinal Immunity}

As the largest compartment of the immune system, the intestine contains anatomical and physiological distinctions of its immune components. The Peyer's patches and the mesenteric lymph nodes comprise organized lymphoid tissues known as the Gut Associated Lymphoid Tissue (GALT). The effector sites of the intestine are the mucosal epithelium and the underlying lamina propria. Within the lamina propria are many different immune cells including activated $\mathrm{T}$ cells, plasma cells, and numerous innate immune cells including mast cells, dendritic cells, eosinophils, and macrophages (Figure 3). A detailed review of the intestinal immune system can be found in Mowat et al. ${ }^{40}$

\section{Butyrate in Intestinal Immunity - Innate}

\section{Mucosal Barrier}

The single layer of intestinal epithelial cells and its adjacent mucous layer serve as the host's first line of intestinal immune 
Table I SCFA G-Protein Coupled Receptors ${ }^{18,27-35}$

\begin{tabular}{|l|l|l|l|}
\hline GPCR & Tissue/Cell Expression & Signaling & Ligands \\
\hline GPR4I, FFAR3 & $\begin{array}{l}\text { Adipose tissue, peripheral blood mononuclear cells (PBMC), pancreas, } \\
\text { spleen and placenta monocytes, neutrophils, and monocyte-derived } \\
\text { dendritic cells }\end{array}$ & $\begin{array}{l}\mathrm{G} \alpha_{i} / \mathrm{G}_{0} \mathrm{~B}- \\
\text { gustducin }\end{array}$ & $\begin{array}{l}\text { Acetate, propionate, butyrate, } \\
\text { formate, pentanoate }\end{array}$ \\
\hline GPR43, FFAR2 & $\begin{array}{l}\text { Intestinal epithelium, monocytes, neutrophils, PBMCs, B and } \\
\text { T lymphocytes, T regulatory cells, and colonic myeloid cells }\end{array}$ & $\begin{array}{l}\mathrm{G} \alpha_{i} / G_{0} \text { and } \\
\mathrm{G} \alpha_{\mathrm{q}} / \mathrm{II} \text { B- } \\
\text { arrestin-2 }\end{array}$ & $\begin{array}{l}\text { Acetate, propionate, butyrate, } \\
\text { pentanoate, hexanoate, } \\
\text { formate }\end{array}$ \\
\hline $\begin{array}{l}\text { GPRI09A, HCAR2, } \\
\text { NIACRI }\end{array}$ & $\begin{array}{l}\text { Colon, ileum, jejunum, duodenum; adipose tissue, lung, spleen, } \\
\text { monocytes, monocyte-derived dendritic cells, dendritic cells, and } \\
\text { macrophages }\end{array}$ & $\begin{array}{l}\mathrm{G} \alpha_{i} / \mathrm{G}_{0} \mathrm{~B}- \\
\text { arrestin-I }\end{array}$ & $\begin{array}{l}\text { Butyrate, } \beta \text {-hydroxybutyrate, } \\
\text { niacin }\end{array}$ \\
\hline
\end{tabular}

Abbreviations: GPR, G-protein coupled receptor; FFAR2, free fatty acid receptor 2; FFAR3, free fatty acid receptor 3; HCAR2, hydroxycarboxylic acid receptor 2; NIACRI, nicotinic acid receptor.

defense by providing a physical barrier against pathogen penetration. It also possesses the ability to secrete antimicrobial peptides by Paneth cells located at the bottom of the intestinal crypts and secretory immunoglobulin A (sIgA). In response to microbes, epithelial cells secrete cytokines and chemokines that recruit immune cells for protective immunity. Within the lamina propria, macrophages and dendritic cells also facilitate the innate immune response in the mucosa. Dysregulation of these immune responses can lead to inflammatory conditions of the intestine.

Tight junctional proteins seal the paracellular space between intestinal epithelial cells, and disassembly of

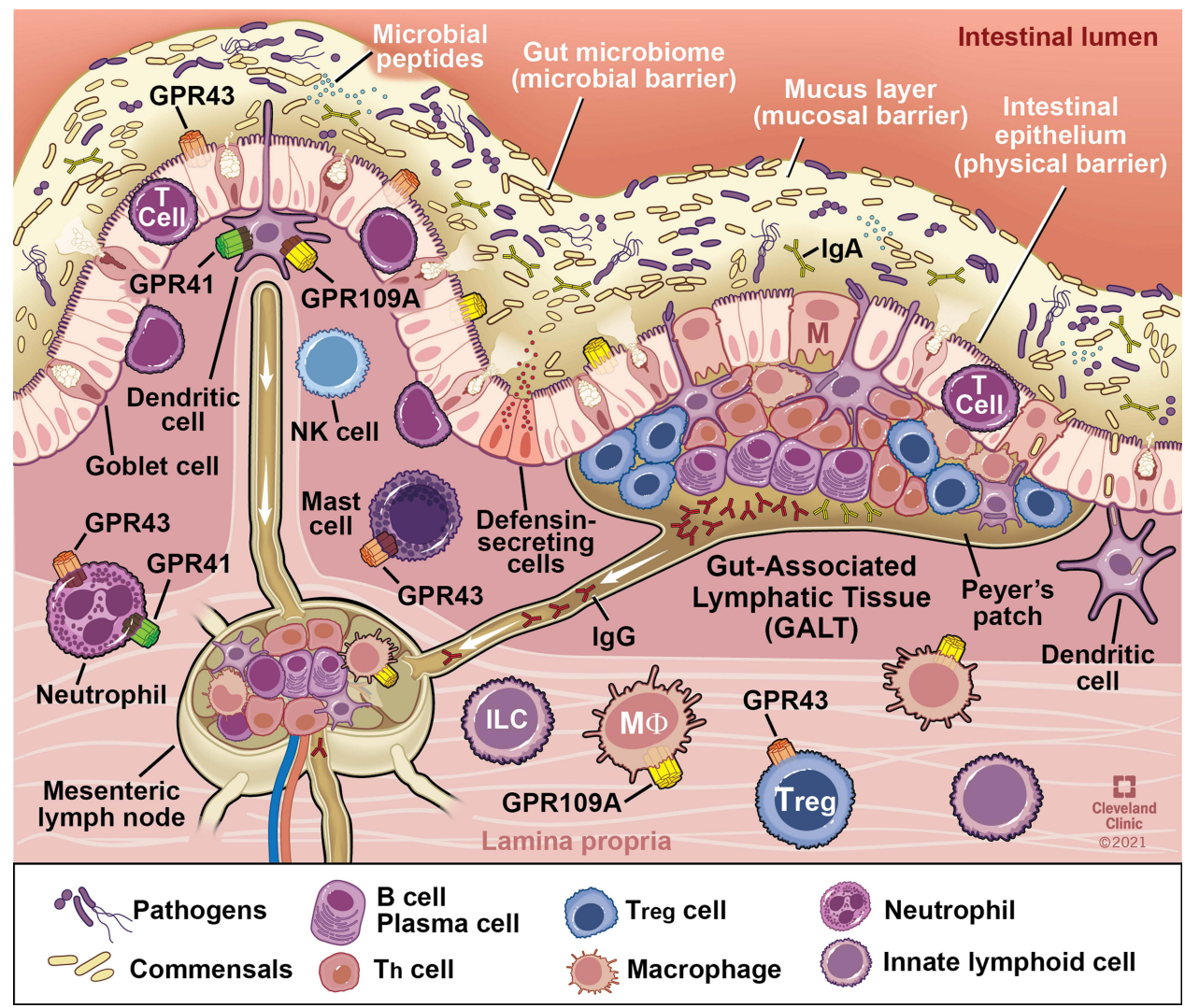

Figure 3 Interaction of the gut microbiota with components of intestinal innate and adaptive immunity. Intestinal immune cells including dendritic and mast cells, neutrophils, $\mathrm{B}$ and T lymphocytes are depicted in representative locations within gastrointestinal mucosa. G-protein coupled receptors in which butyrate serves as a ligand are present on major immune cells and function as key link for butyrate mediated modulation of immune function. Reprinted with permission, Cleveland Clinic Center for Medical Art \& Photography @2021. All Rights Reserved. ${ }^{163}$ 
these junctional proteins can allow for bacteria and bacterial byproducts to translocate from the gut lumen into systemic circulation. Butyrate supports intestinal integrity as demonstrated in in vitro and in vivo experimental models. Various intestinal cell models (eg, Caco-2 human intestinal cells, ${ }^{41-43}$ E12 human colon cells ${ }^{44}$ ) of inciting conditions (eg, lipopolysaccharide (LPS), ${ }^{45}$ ethanol $^{41,42}$ ) demonstrate butyrate treatment protects against functional disruption of intestinal epithelial integrity using methods of transepithelial electrical resistance (TER) and permeability of fluorescein-isothiocyanate (FITC)-dextran. Multiple mechanisms have been demonstrated for butyrate's direct effects on the intestinal epithelial barrier. Increased TJ reassembly and TER restoration was due to butyrate's induction of AMP-activated protein kinase (AMPK) activity. ${ }^{41,43,46}$ During exposure to LPS, butyrate's protection against LPS-induced TER reduction and paracellular permeability coincided with less activation of NLRP3 inflammasome and autophagy via butyrate's HDAC activity. ${ }^{45}$ Butyrate has also been shown to stabilize hypoxia-inducible factor (HIF), a transcription factor that coordinates low oxygen in the colonic epithelium to regulate intestinal barrier function. ${ }^{47}$ Positive effects of butyrate on TJ proteins are dose dependent, with lower doses demonstrating benefit. In vitro studies with E12 mucus-producing epithelial cells demonstrated that lower (1-10 mM), but not higher (50-100 mM), butyrate dosing prevented alterations in TER, FITC-dextran permeability, and mucus production by goblet cells. ${ }^{44}$ Higher butyrate dosing in Caco-2 monolayers $(8 \mathrm{mM})$ was cytotoxic reducing TER, increasing FITC permeability, and inducing apoptosis compared to lower dosing $(2 \mathrm{mM}){ }^{48} \mathrm{In}$ a mouse model of ethanol exposure, the amount and delivery method of tributyrin, a butyrate prodrug, paradoxically impacted the effect on intestinal TJ proteins and liver injury. Higher doses $(10 \mathrm{mM})$ provided daily in the food supply increased liver injury and steatosis compared to lower doses provided by oral gavage, despite both methods and doses protecting against ethanol-induced disassembly of intestinal TJ proteins. ${ }^{41}$ Together, these data support the notion that butyrate has a direct beneficial effect on supporting the intestinal epithelial barrier integrity in a dose-dependent manner.

\section{Mucosal Inflammation}

The intestinal immune system must remain tolerant of commensal microbes in order to maintain homeostasis. Pattern recognition receptors (PRRs), including toll-like receptors (TLRs) and nucleotide-binding oligomerization domain-containing protein 2 (NOD2) are expressed by intestinal epithelial cells and immune cells within the lamina propria. These evolutionary conserved receptors recognize microbially-associated molecular patterns (MAMPS) and trigger diverse innate immune responses. Some PRRs also recognize damage-associated molecular patterns (DAMPS) released during cellular stress or tissue injury. Toll like receptors $(1,2,4,5$, and 6) are located primarily in the plasma membrane and interact with components of microbial pathogens. Despite having different ligands, PRRs share signaling pathways that ultimately activate pro-inflammatory transcription factors, such as $\mathrm{NF}-\mathrm{kB}$, which controls expression of genes encoding for proinflammatory cytokines, chemokines, inducible inflammatory enzymes, adhesion molecules, growth factors, acute phase proteins, and immune receptors. ${ }^{49}$ Thus, it is essential that there is tight regulation of PRR activity to avoid excessive inflammation and dysregulated immune responses. A more detailed review of PRRs can be found in Burgueno et al. ${ }^{50}$

Multiple human and animal studies demonstrate that in response to butyrate within the intestine proinflammatory cytokines such as IFN- $\gamma$, TNF- $\alpha$, IL- 6 , and IL- 8 are inhibited, and anti-inflammatory cytokines IL-10 and TGF- $\beta$ are induced. ${ }^{40}$ Butyrate has a long-standing history of being anti-inflammatory through its inhibition of NF- $\mathrm{BB}$, as demonstrated in several in vitro and in vivo studies. ${ }^{51-55}$ Butyrate, a ligand for GPR109A, inhibited LPS-induced activation of NF-KB in normal colon cells. ${ }^{34}$ The nuclear transcription factor PPAR $\gamma$, which antagonizes NF- $\mathrm{BB}$, was reported to be upregulated by butyrate in HT-29 colonic epithelial cells. ${ }^{56}$ Butyrate suppression of reactive oxygen species through support of the antioxidant system has been suggested as a means for butyrate inactivation of NF- $\mathrm{kB}$ inflammatory signaling. ${ }^{57}$ In a mouse model of chronic-binge ethanol feeding which induces oxidative stress, tributyrin co-supplementation mitigated losses in gene expression of superoxide dismutase 2 (SOD2), thioredoxin (TRX1) and protected against ethanol-induced NOX $1 .{ }^{58}$

\section{Mucosal Antimicrobial Peptides}

Antimicrobial peptides (AMP), including defensins, cathelicidins, and C-type lectins (eg, regenerating [Reg] isletderived protein family), are highly conserved, evolutionary, and are important in innate immunity at intestinal mucosal surfaces. Butyrate has been shown to promote production of 
AMPs by intestinal epithelial cells through its interaction with GPR43, ${ }^{59}$ activation of MEK/ERK and JNK pathways, ${ }^{60}$ and its cell proliferation mechanisms. ${ }^{60}$ Butyrate was also shown to increase AMPs secreted by macrophages. Acting via its HDAC3 inhibitory function, butyrate drove monocyte to macrophage differentiation and induced macrophage production of AMPs, S100A8 and S100A9 genes and calprotectin expression, in the absence of increased proinflammatory cytokine response, which led to enhanced bactericidal function in vitro and in vivo. ${ }^{61}$

\section{Butyrate and Intestinal Innate Immune Cells Neutrophils}

As first responders into an inflammatory site, neutrophils are responsive to pathogens by producing cytokines that begin coordinating the recruitment and activation of other immune cells. Several neutrophil functions are modulated by SCFA. By regulating the production of inflammatory mediators, such as TNF $\alpha$ and IL-17, SCFA modify neutrophil recruitment. ${ }^{62}$ Neutrophil chemotaxis has been shown to be regulated through the SCFA activation of the GPR43 receptor in neutrophils. ${ }^{63,64}$ SCFA may also modify neutrophil functions such as their phagocytic capacity and ability to produce and release reactive oxygen species and nitric oxide. ${ }^{65}$ Butyrate and propionate induce apoptosis in both activated and non-activated neutrophils, which depends on activation of caspases but not $\mathrm{G} \alpha_{\mathrm{i} / \mathrm{o}}$ and $\mathrm{G} \alpha_{\mathrm{q}}$ pathways, suggesting independence of SCFA receptors. ${ }^{66}$

\section{Macrophages}

Intestinal macrophages are the most abundant immune cells within the lamina propria where they are important for the induction of innate immune responses. In bone marrowderived macrophages stimulated with LPS, butyrate decreased secretion of IL-6, IL-12p40, and nitric oxide to a greater extent than acetate or propionate in a dose dependent manner, suggesting butyrate has anti-inflammatory effects on macrophages. ${ }^{30}$ Butyrate treatment in macrophages isolated from the colonic lamina propria and stimulated with LPS, had less inflammatory response exhibited by decreased IL-6 secretion and mRNA expression, IL-12 and inducible nitric oxide synthase, but butyrate had no effect on TNF $\alpha$ or MCP- $1 .{ }^{30}$ Similar effects were noted in macrophages isolated from the colonic lamina propria of mice treated with antibiotics and butyrate, suggesting that butyrate modulates immune responses of colon lamina propria macrophages. These responses were dependent on HDAC inhibition but not TLRs and GPCRs. ${ }^{30}$ Contrary to these studies, SCFA alone or in combination, and/or combined with TLR agonists, led to pro-inflammatory effects by inducing IL-1 $\beta$, IL-6, CXCL8/IL-8 in human peripheral blood mononuclear cells. ${ }^{67}$ Thus, the divergences on the inflammatory effects of butyrate appears to depend on the cell type studied and the conditions, environment, and type of stimulation. $^{68}$

\section{Mast Cells}

Mast cells, which are abundant within the GI tract mucosa and submucosa, are known to play a role in GI diseases such as food allergy, as well as certain forms of colitis and Crohn's disease. ${ }^{69-72}$ Provision of dietary fibers and prebiotics that are fermented into SCFA have been tested in animal models of food allergens. Benefits relating to anaphylaxis scores and IgE concentrations were noted with fiber supplementation, or the addition of acetate or butyrate to animal drinking water, suggesting the production of SCFA from fiber as the mediating effector on mast cells. ${ }^{73}$ Similarly, prebiotics tested in mouse models of colitis which led to increased fecal SCFA levels were linked with protection of the intestinal barrier, and a reduction in inflammation and inflammatory cytokines. ${ }^{74}$ Germinated barley, a prebiotic that is fermented into SCFA, reduced colonic mast cell recruitment when fed to rats in an experimental colitis model $;{ }^{75}$ and ulcerative colitis patients fed germinated barley had reduced inflammation and an improved clinical activity index. ${ }^{76,77}$ When testing the direct effects of butyrate on mast cells, jejunal mucosa of pigs treated with butyrate had reduced mast cell degranulation and gene expression of proinflammatory cytokines. ${ }^{78}$ These data corroborate a previous report demonstrating that the direct effect of butyrate on mast cells was due to the MAPK signaling pathway and inhibition of JNK phosphorylation. ${ }^{79}$

\section{Innate Lymphoid Cells}

Innate lymphoid cells (ILC) are regulated by multiple endogenous mammalian cell-derived factors and integrate innate and adaptive immune responses to assist in maintaining physiological homeostasis. ${ }^{80}$ Nontoxic ILCs consist of three distinct groups: ILC1, 2, and 3 and are defined based on their transcription factor requirements, effector cytokine expression, and other distinct effector functions. ${ }^{80}$ ILC3s express retinoid-related orphan receptor $\gamma \mathrm{t}(\mathrm{ROR} \gamma \mathrm{t})$ and 
produce IL-17A, IL-22, lymphotoxin, and GM-CSF. ${ }^{81}$ While ILC3s increase in population in the distal small intestinal lamina propria, they were found to have distinctive distribution in proximal versus ileal Peyer's patches in mice based on specific transcription factor expression; and the suppression of ROR $\gamma \mathrm{t}+\mathrm{ILC} 3$ in ileal Peyer's patches was linked with the presence of butyrate. ${ }^{82}$ Butyrate levels, which were higher in the ileum than jejunum as expected, were inversely associated with ROR $\gamma \mathrm{t}+\mathrm{ILC} 3 \mathrm{~s}$ and IL-22 expression, suggesting that butyrate was a regionally specialized factor suppressing ILC3s in terminal ileal Peyer's patches. ${ }^{82}$ A study in mice found butyrate supplementation and subsequent increased colonic butyrate levels, promoted IL-22 production from ILCs in the lamina propria and mesenteric lymph nodes through histone deacetylase inhibition and GPR41 by promoting aryl hydrocarbon receptor and hypoxia-inducible factor $1 \alpha^{83}$ IL-22 aids in protecting the intestine against inflammatory injury by inducing AMPs and supporting the intestinal barrier. ${ }^{84,85}$

\section{Butyrate in Intestinal Immunity - Adaptive}

Butyrate has been shown to play an important role in an adaptive immune response via two distinct pathways: firstly, from the effect of butyrate on monocyte-derived dendritic cells (DC), ${ }^{32,86-88}$ and secondly, through butyrate's direct effect on T lymphocytes. ${ }^{89,90}$

\section{Dendritic Cells}

As specialized antigen presenting cells, dendritic cells (DC) are in direct contact with the gut microbiota and its metabolites. In the intestine, DC induce adaptive immune responses in primary $\mathrm{T}$ cells bridging the gap between innate and adaptive immunity. ${ }^{91,92}$ Immature DC help maintain a state of immune tolerance, and mature DC can activate immune responses. Butyrate treatment is reported to have a significant impact on differentiation, maturation, and overall $\mathrm{T}$ lymphocyte stimulating effects of human monocyte derived DC. ${ }^{86,90}$ In vitro studies found butyrate in the presence of inducers (eg, LPS, TNF- $\alpha$ ) affected the differentiation of DC and induced an immunosuppressive effect in DC derived from human monocytes and inhibited $\mathrm{T}$ cell proliferation. $^{21,86}$ Butyrate treatment at low non-toxic doses reduced the expression of mature DC surface markers for mature DC (CD80, CD83, CD40, CD45, MHC class II molecules). ${ }^{21,86}$ Multiple studies have also explored the modulatory effect of butyrate on cytokine production by
DC, and reported that butyrate treatment inhibited the production of pro-inflammatory cytokine IL-12 when DC were stimulated. $^{21,86,93}$ Liu et al reported that butyrate treatment resulted in 3-fold decrease in IL-12 secretion, 5-fold decrease in IFN- $\gamma$, and 11-fold increase in IL-10 secretions from DC. ${ }^{21}$ Butyrate-stimulated DC significantly promoted IL-10 production by priming Type-1 regulatory $\mathrm{T}$ cells (Tr1). ${ }^{93}$ Through activation of GPR109a in macrophages and DC, butyrate plays a key role in maintenance of proand anti-inflammatory $\mathrm{T}$ lymphocytes, as butyrate potentiates conversion of naïve T cells to FoxP3+ regulatory T cells while suppressing IFN- $\gamma+\mathrm{T}$ cells. ${ }^{33,87}$ Kaiser et al also reported that butyrate rendered DC metabolically less active by significantly antagonizing LPS-induced extracellular acidification rate, as well as by significantly reducing mitochondrial oxygen consumption rate in butyrate treated DC at baseline. $^{93}$

\section{T and B Lymphocytes}

Independent of its immunomodulatory effects mediated by DC and macrophages, butyrate also has dose-dependent direct effects on $\mathrm{T}$ lymphocytes. ${ }^{89,94,95}$ By utilizing a combination of both in-vivo and in-vitro experiments, Arpaia et al concluded that butyrate can boost extrathymic Treg-cell generation by acting directly on $\mathrm{T}$ cells, and in the absence of DC, this effect was mediated by an increase in the extrathymic CNS1 (Conserved Noncoding Sequence-1)-dependent differentiation of Treg cells. ${ }^{89}$ Butyrate via its HDAC function, caused increased Foxp3 protein acetylation, which ultimately resulted in higher Foxp3 protein levels in Treg cell culture. ${ }^{89}$ Kespohl et al studied the effect of different butyrate concentrations $(0.1 \mathrm{mM}$ to $1 \mathrm{mM}$ for in-vitro, and $50 \mathrm{mM}$ to $200 \mathrm{mM}$ for invivo via oral route) on $\mathrm{T}$ cell-mediated immune response utilizing CD4+ $\mathrm{T}$ cells. ${ }^{95}$ They reported that at lower concentrations $(0.1$ to $0.5 \mathrm{mM})$ butyrate facilitated differentiation of Tregs both in-vitro and in-vivo, while at a higher concentration $(1 \mathrm{mM})$ butyrate induced the expression of the transcription factor T-bet which resulted in IFN- $\gamma$-producing Tregs or conventional T cells. ${ }^{95}$ In addition to its direct effect on CD4+ T lymphocytes, butyrate also directly modulated gene expression in CD8+ cytotoxic $\mathrm{T}$ lymphocytes and altered gene expression of effector molecules such as IFN- $\gamma$ in a dose dependent manner. ${ }^{96,97}$ Butyrate also improved the memory potential and enhanced recall capacity of $\mathrm{CD} 8+\mathrm{T}$ memory cells (Tmem) through reprogramming cellular mitochondrial metabolic flux. ${ }^{98,99}$ SCFA have also been shown to 
promote IL-10 production from Th1 cells via GPR43 mediated effect, which plays an important role in maintenance of intestinal homeostasis and Gpr43-/- CBir1 Tg Th1 cells have been reported to induce severe colitis in mice. ${ }^{100}$ Recent studies have also investigated the effect of butyrate on regulatory B lymphocytes (B10) and found butyrate to have anti-inflammatory properties resulting from induction of $\mathrm{IL}-10$ producing $\mathrm{B}$ cells. ${ }^{101,102}$ However, conflicting data exist, as other studies which utilized different doses of butyrate reported direct inhibitory effect of butyrate on B10 cells, and speculated that previous reports on B10 induction by butyrate likely resulted from indirect effects via serotonin-derived metabolite 5-hydroxyindole-3-acetic acid. ${ }^{103}$ A study by Daien et al showed that the SCFA acetate promoted B10 cell which resulted in an anti-inflammatory effect. ${ }^{103}$ Butyrate has been reported to cause B-cell intrinsic epigenetic modulation of antibody response by HDAC inhibitory effect and enhancing class-switch DNA recombination, which results in inhibition of autoimmune response. ${ }^{104}$ SCFA also induce antibody response by stimulating intestinal mucosal $\mathrm{IgA}$ responses and systemic $\operatorname{IgG}$ responses. ${ }^{105}$ Overall, a substantial level of evidence has been reported supporting the role of SCFA in general and butyrate in specific in various stages of adaptive immune responses.

\section{Clinical Significance for Select GI Diseases \\ Inflammatory Bowel Diseases}

Inflammatory bowel diseases (IBD) are chronic intestinal inflammatory disorders with two main subtypes: Crohn's disease and ulcerative colitis. ${ }^{106}$ Although exact pathogenesis of IBD is not completely understood, IBD involves complex interactions among various influencing factors of genetics, gut microbiota and mucosal immunity via both innate and adaptive immune responses. ${ }^{106}$ In both subtypes of IBD, a reduction in butyrate producing gut microbes has been reported. ${ }^{107,108}$ As it has been described in our previous detailed discussion in this review, butyrate has multi-stage modulating effects on intestinal defense mechanisms which include protection of the intestinal mucosal barrier through promotion of tight junctional proteins in the intestinal epithelium, support of innate and adaptive immune responses, as well as inhibition of oxidative stress by reducing cyclooxygenase-2 (COX-2) levels, and improved detoxification of hydrogen peroxide $\left(\mathrm{H}_{2} \mathrm{O}_{2}\right)$ by induction of catalase. ${ }^{109,110}$ Since the late 20th century when the implication of butyrate in colitis was first highlighted, a series of experimental and clinical studies have been conducted. ${ }^{110,111}$

\section{Experimental Studies with IBD Modeling}

In this section, we discuss the studies exploring the butyrate effect in IBD-specific processes. For the broader and more detailed overview of the butyrate effect on overall immune function please refer to the earlier section of this review. Although some of these previously discussed concepts do have significant application in IBD pathogenesis, they will not be discussed in the current section to avoid redundancy. Intestinal mucosal ulceration is one of the major manifestations of IBD, and butyrate's effects on intestinal epithelial cell growth and cell death processes have been well-documented. Depending on the overall homeostatic condition, such as the presence or absence of an alternate energy source, butyrate has been shown to have either growth stimulatory or apoptotic properties for human colonic epithelial cells. ${ }^{112}$ In addition, butyrate has been shown to reduce DNA damage from oxidative stress in both human and rat-derived colonocyte cultures. ${ }^{113,114}$ Early life exposures such as breastfeeding has been reported to have a protective role against development and pathogenesis of IBD. ${ }^{115}$ Gao et al studied this mechanism further and analyzed this effect by utilizing immature human enterocytes. ${ }^{116}$ Their team reported that breast milk induced the anti-inflammatory environment in newborns' GI tract via its metabolite butyrate by inducing the expression of genes for both tight junctional proteins and mucus production. ${ }^{116}$ As discussed in earlier section of innate immunity, inflammasomes, a group of cytosolic protein complexes which regulate the balance of commensal bacteria and protect from pathogenic organisms, also have a potential role in pathogenesis of IBD. ${ }^{117,118}$ While inflammasomes are protective when intestinal barrier is intact, once the barrier is disrupted by gut dysbiosis, inflammasomes' activation and recruitment of immune cells are associated with mucosal inflammation which is another major pathophysiologic mechanism for ongoing inflammation in IBD. ${ }^{118}$ Butyrate has been shown to modulate pro-inflammatory signals and inhibit several nucleotide-binding oligomerization domain-like receptor-3 (NLRP3) inflammasome markers in an in vitro co-culture model of intestinal inflammation. ${ }^{118,119}$ One study reported that butyrate significantly reduced IL- 8 secretion, and therefore IL- 8 mediated chemotaxis, when IL- $1 \beta$ was inhibited by other IBD therapies (such as 5-ASA), highlighting a mechanism behind the inconsistent clinical response by butyrate alone and potential for combining butyrate with 
other treatment modalities of IBD. ${ }^{120,121}$ Geirnaert et al augmented the microbiota derived from Crohn's disease patients by adding butyrate-producing bacteria ( $F$. prausnitzii, Butyricicoccus pullicaecorum, and the mix of six butyrateproducers) which improved epithelial barrier integrity in vitro. ${ }^{122}$

\section{Animal Studies}

In animal models, preventative and therapeutic potential of butyrate for colitis has been studied either by modulating butyrate levels through dietary supplementation of butyrateyielding prebiotics, sodium butyrate, or tributyrin, or through direct sodium butyrate instillation via rectal enemas. In a DSSinduced colitis model in male outbred-CD-1 mice, the dietary provision of baked corn and bean snack (20-40 g/kg body weight) resulted in the highest concentration of butyrate in the cecum and feces, and an anti-inflammatory effect by downregulating IL-1 receptor, TLR receptors and TNF-alpha pathways. ${ }^{123}$ Smith et al reported that $150 \mathrm{mM}$ of butyrate supplementation in drinking water resulted in increased colonic regulatory $\mathrm{T}$ cells (cTregs) frequency and number in the germ free mice. ${ }^{124}$ Similarly, in another study byZhang et al, they studied the effect of butyrate supplementation in a rat model of colitis and reported that butyrate supplementation played an important role in regulating Treg and Th17 cell balance and exerted protective effect against development of IBD. ${ }^{125}$ Impaired intestinal barrier function and increased permeability is considered one of the key mechanisms in development of IBD, and as discussed earlier butyrate supplementation has been shown to mitigate this effect in multiple in-vitro animal models. ${ }^{42,126}$ In IL-10 deficient mice which are prone to development of colitis, butyrate supplementation has been shown to provide protection against colitis through reducing the amount of colitogenic IgA-coated bacteria. ${ }^{127}$ Butyrate enemas have also been shown to stimulate mucosal repair and healing, and exert anti-inflammatory effect in intestinal epithelium. ${ }^{128-130}$ Burrello et al reported that fecal microbiota transplantation with healthy stool in mice exposed to chronic intestinal inflammation decreased colonic inflammation, effects which are mediated through $\mathrm{T}$ cell modulation. $^{131,132}$

\section{Human Studies and Therapeutic Application}

Human studies for therapeutic use of butyrate in IBD have been implemented since late 20th century. In 1992 Scheppach et al performed a clinical trial in which
$100 \mathrm{mMol} / \mathrm{L}$ of butyrate via rectal enema was compared with placebo for distal ulcerative colitis and reported that butyrate improved all parameters related to colitis including clinical indices with decreased stool frequency and blood in stool, and endoscopic and histological inflammatory grading. ${ }^{133}$ Other clinical trials which followed reported mixed results, ranging from no to some butyrate effectiveness, although not at the degree of therapeutic value. ${ }^{134,135}$ Hamer et al studied the effect of butyrate in low grade inflammation in ulcerative colitis patients in remission, and reported only minor improvements in inflammatory and oxidative stress parameters after rectal enema of $10 \mathrm{mM}$ sodium butyrate for 20 days. ${ }^{136}$ In a systematic review and meta-analysis of eight randomized clinical trials on a total of 227 patients with UC, Jamka et al reported that current limited evidence does not support the use of butyrate enemas in UC. ${ }^{137}$ Due to inconsistencies in the response of butyrate therapy, perhaps at some degree due to variability in dosages, duration and a standardization of the formula, current applicability of butyrate in IBD is considered as an add-on supplementary therapy at best. ${ }^{121,138}$ One area in which butyrate has shown more consistent effectiveness is in cases of diversion colitis, a post-surgical manifestation when a part of colon is out of continuity and butyrate depletion is thought to be the major factor for driving inflammation. ${ }^{139}$ Although surgical treatment with either reconnection or resection of the diverted colon is a more definitive treatment, butyrate enema has been shown to have therapeutic value when medical management is considered. ${ }^{140}$ It should be noted that due to overall discrepancy in the evidence, there remains a lack of SCFA or butyrate related guidelines from GI and Nutrition Societies. ${ }^{141,142}$ Although most studies utilizing the gut microbiota reprogramming by means of probiotics, prebiotics, and synbiotics, ${ }^{143}$ or the fecal microbiota transplantation in patients with $\mathrm{UC}$ or $\mathrm{CD}$ have produced positive results, ${ }^{144-146}$ the exact mechanism behind this complex interaction between the gut microbiome and the host is not clearly understood, requiring further investigations to determine the role and implications of butyrate in management of this complex inflammatory disorder.

\section{Colorectal Cancer}

Patients with colorectal cancer have been reported to have low levels of SCFA including butyrate. ${ }^{147}$ As mentioned, butyrate has been reported to have a paradoxical effect on the proliferation of intestinal epithelial cells, supporting 
healthy cells in homeostasis, but suppressing the hyperproliferation induced by cancer. ${ }^{12,148,149}$ Sodium butyrate has been shown to induce apoptosis in human colonic cancer cell lines in a p-53 independent pathway. ${ }^{150}$ Butyrate also provides protection against oxidative stress and DNA damage. ${ }^{113}$ Butyrate has also been reported to have cancer protective effects via several pathways which include suppression of Neuropilin-1 (NRP-1), ${ }^{151}$ inhibition of mitogen-activated protein kinase (MAPK) signaling pathway, ${ }^{152}$ differential regulation of Wnt- $\beta$-catenin signaling pathway, ${ }^{153,154}$ and upregulation of microRNA miR-203 and promotion of cell apoptosis, ${ }^{155}$ and inhibition of pro-proliferative miR-92a. ${ }^{156}$ Due to a wellestablished role of dietary pattern with colorectal cancer, the majority of human trials have investigated interventions by means of modifying dietary fiber intake and reported reduced risk of colorectal cancer recurrence. ${ }^{157,158}$

Recent extensive meta-analyses' have confirmed these trends and reported a strong association of colorectal cancer risk with dietary pattern and specifically with a low fiber, high fat and simple sugar containing diet. ${ }^{159,160}$
Although there are several possible theories through which the anti-colon-cancer effect of the high fiber diet is thought to be mediated, the evidence from in-vitro studies have shown that butyrate plays a major role as an important intermediary metabolite in this pathway. ${ }^{140,161,162}$ More research is needed to show the direct effects of gut microbially generated butyrate on anticolon cancer effects.

\section{Conclusion and Future Perspectives}

In summary, butyrate is a key gut microbial metabolite which mediates the effects of the gut microbiota on the immune system, and not only does it play a key role in the maintenance of intestinal immune homeostasis, but it also has future potential therapeutic implications for a spectrum of gastrointestinal and systemic disorders. Figure 4 summarizes what is currently known regarding butyrate's role within the intestinal immune system. Certain challenges remain due to its low bio-availability, short half-life, variable levels in healthy individuals, as well as the lack of consistent clinical data supporting its value as a therapeutic option. Future studies including rigorous

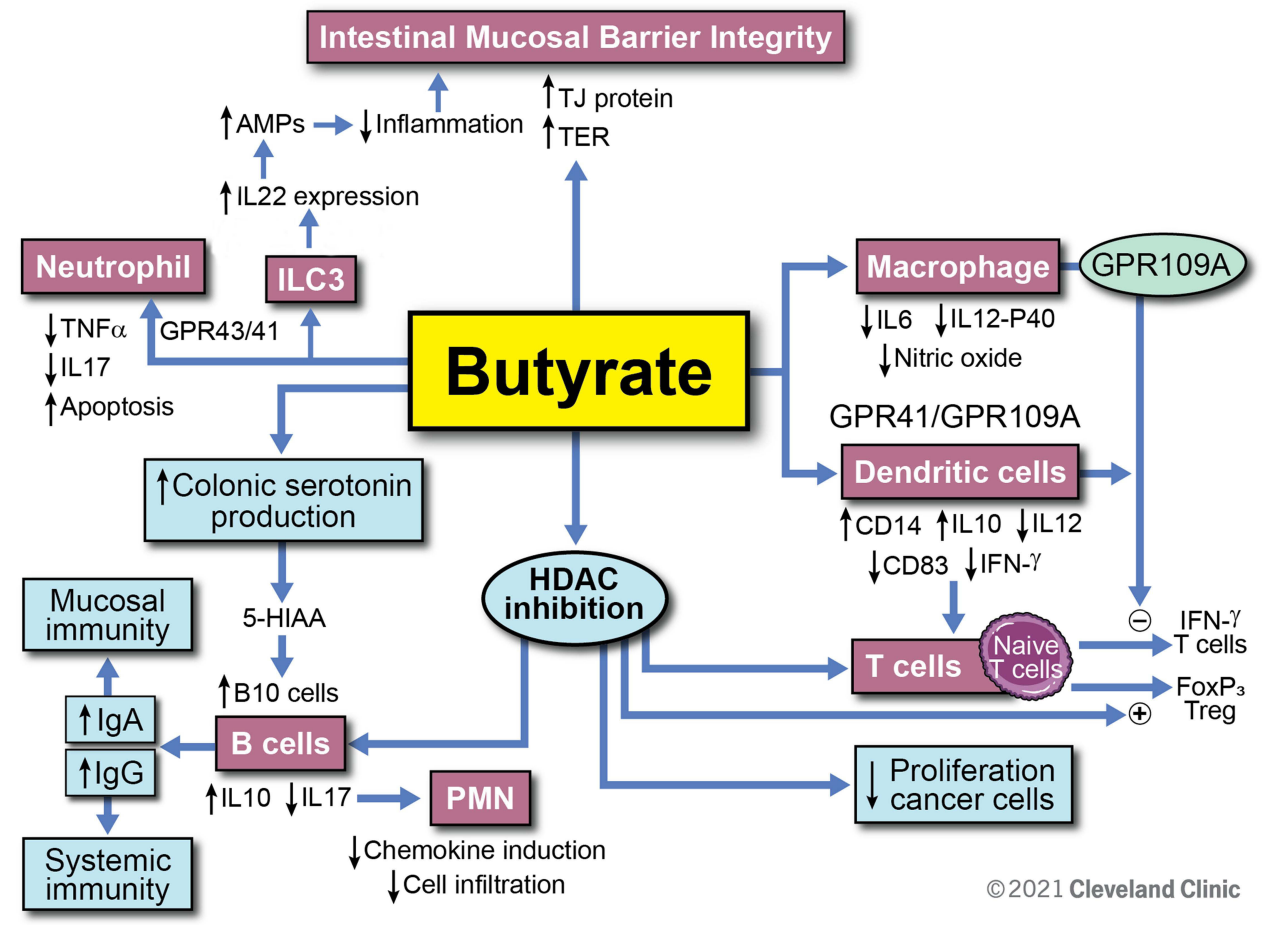

Figure 4 Overview of butyrate modulatory effects on immune function. Butyrate enhances the intestinal mucosal barrier by directly inducing tight junctional proteins in the epithelium. This effect is further augmented by butyrate's induction of IL-22 secretion from ILC3 cells. Through interaction with GPCR 43 and 4 I, butyrate inhibits the proinflammatory cytokine secretion from neutrophils. Butyrate has direct effects on macrophages and dendritic cells via GPCR and modulates T cell function by increasing Foxp3 T cells while inhibiting IFN-y producing T cells. Butyrate increases serotonin production and is also an inhibitor of HDAC. It modulates B cell function through these routes and increases anti-inflammatory cytokine IL-I0 while it decreases IL-I7. By increasing IgA and IgG antibody response from B cells, butyrate augments specific immunity and inhibits autoimmunity. Reprinted with permission, Cleveland Clinic Center for Medical Art \& Photography @2021. All Rights Reserved. ${ }^{163}$ 
experimental models and explorations are necessary to further characterize the potential of butyrate as a preventative or therapeutic option for inflammatory and immune-mediated intestinal conditions.

\section{Disclosure}

This work was supported by a National Institutes of Health grant (no. R01AA028043- 01A1 (Cresci) and 2T32DK083251-11A1 (MPI). The authors report no conflicts of interest in this work.

\section{References}

1. Rinninella E, Raoul P, Cintoni M, et al. What is the healthy gut microbiota composition? A changing ecosystem across age, environment, diet, and diseases. Microorganisms. 2019;7(1):14. doi:10.3390/microorganisms7010014

2. Sender R, Fuchs S, Milo R. Revised estimates for the number of human and bacteria cells in the body. PLoS Biol. 2016;14(8): e1002533. doi:10.1371/journal.pbio.1002533

3. Human Microbiome Project C. Structure, function and diversity of the healthy human microbiome. Nature. 2012;486 (7402):207-214. doi:10.1038/nature 11234

4. Kapourchali FR, Cresci GAM. Early-life gut microbiome-The importance of maternal and infant factors in its establishment. Nutr Clin Pract. 2020;35(3):386-405. doi:10.1002/ncp.10490

5. Cresci GA, Bawden E. Gut microbiome. Nutr Clin Pract. 2015;30 (6):734-746. doi:10.1177/0884533615609899

6. Wilson AS, Koller KR, Ramaboli MC, et al. Diet and the human gut microbiome: an international review. Dig Dis Sci. 2020;65 (3):723-740. doi:10.1007/s10620-020-06112-w

7. Shi N, Li N, Duan X, Niu H. Interaction between the gut microbiome and mucosal immune system. Mil Med Res. 2017;4:14.

8. Bandeira A, Mota-Santos T, Itohara S, et al. Localization of gamma/delta $\mathrm{T}$ cells to the intestinal epithelium is independent of normal microbial colonization. $J$ Exp Med. 1990;172 (1):239-244. doi:10.1084/jem.172.1.239

9. McDermott AJ, Huffnagle GB. The microbiome and regulation of mucosal immunity. Immunology. 2014;142(1):24-31. doi:10.1111/imm.12231

10. Hooper LV, Stappenbeck TS, Hong CV, Gordon JI. Angiogenins: a new class of microbicidal proteins involved in innate immunity. Nat Immunol. 2003;4(3):269-273. doi:10.1038/ni888

11. Canani RB, Costanzo MD, Leone L, Pedata M, Meli R, Calignano A. Potential beneficial effects of butyrate in intestinal and extraintestinal diseases. World J Gastroenterol. 2011;17 (12):1519-1528. doi:10.3748/wjg.v17.i12.1519

12. Riviere A, Selak M, Lantin D, Leroy F, De Vuyst L. Bifidobacteria and butyrate-producing colon bacteria: importance and strategies for their stimulation in the human gut. Front Microbiol. 2016;7:979. doi:10.3389/fmicb.2016.00979

13. Garcia-Miguel M, Gonzalez MJ, Quera R, Hermoso MA. Innate immunity modulation by the IL-33/ST2 system in intestinal mucosa. Biomed Res Int. 2013;2013:142492. doi:10.1155/2013/ 142492

14. Lazar V, Ditu LM, Pircalabioru GG, et al. Aspects of gut microbiota and immune system interactions in infectious diseases, immunopathology, and cancer. Front Immunol. 2018;9:1830. doi:10.3389/fimmu.2018.01830

15. Goncalves P, Martel F. Regulation of colonic epithelial butyrate transport: focus on colorectal cancer. Porto Biomed J. 2016;1 (3):83-91. doi:10.1016/j.pbj.2016.04.004
16. Roychowdhury S, Glueck B, Han Y, Mohammad MA, Cresci GAM. A designer synbiotic attenuates chronic-binge ethanol-induced gut-liver injury in mice. Nutrients. 2019;11 (1):97.

17. Cresci GA, Thangaraju M, Mellinger JD, Liu K, Ganapathy V. Colonic gene expression in conventional and germ-free mice with a focus on the butyrate receptor GPR109A and the butyrate transporter SLC5A8. J Gastrointest Surg. 2010;14(3):449-461. doi:10.1007/s11605-009-1045-x

18. Parada Venegas D, De la Fuente MK, Landskron G, et al. Short Chain Fatty Acids (SCFAs)-mediated gut epithelial and immune regulation and its relevance for inflammatory bowel diseases. Front Immunol. 2019;10:277. doi:10.3389/fimmu.2019.00277

19. Dalile B, Van Oudenhove L, Vervliet B, Verbeke K. The role of short-chain fatty acids in microbiota-gut-brain communication. Nat Rev Gastroenterol Hepatol. 2019;16:461-478.

20. Bachmann C, Colombo JP, Berüter J. Short chain fatty acids in plasma and brain: quantitative determination by gas chromatography. Clin Chim Acta. 1979;92(2):153-159. doi:10.1016/0009-8981(79)90109-8

21. Liu L, Li L, Min J, et al. Butyrate interferes with the differentiation and function of human monocyte-derived dendritic cells. Cell Immunol. 2012;277(1-2):66-73. doi:10.1016/j.cellimm.2012. 05.011

22. Velázquez OC, Lederer HM, Rombeau JL. Butyrate and the colonocyte. Production, absorption, metabolism, and therapeutic implications. Adv Exp Med Biol. 1997;427:123-134.

23. Dass NB, John AK, Bassil AK, et al. The relationship between the effects of short-chain fatty acids on intestinal motility in vitro and GPR43 receptor activation. Neurogastroenterol Motil. 2007;19(1):66-74. doi:10.1111/j.1365-2982.2006.00853.x

24. Cherbut C, Ferrier L, Rozé C, et al. Short-chain fatty acids modify colonic motility through nerves and polypeptide YY release in the rat. Am J Physiol. 1998;275:G1415-G1422.

25. Fukumoto S, Tatewaki M, Yamada T, et al. Short-chain fatty acids stimulate colonic transit via intraluminal 5-HT release in rats. Am J Physiol Regul Integr Comp Physiol. 2003;284(5):R1269R1276. doi:10.1152/ajpregu.00442.2002

26. Lee C, Kim BG, Kim JH, Chun J, Im JP, Kim JS. Sodium butyrate inhibits the NF-kappa B signaling pathway and histone deacetylation, and attenuates experimental colitis in an IL-10 independent manner. Int Immunopharmacol. 2017;51:47-56. doi:10.1016/j.intimp.2017.07.023

27. Agus A, Denizot J, Thevenot J, et al. Western diet induces a shift in microbiota composition enhancing susceptibility to adherent-invasive E. coli infection and intestinal inflammation. Sci Rep. 2016;6:19032.

28. Ang Z, Er JZ, Ding JL. The short-chain fatty acid receptor GPR43 is transcriptionally regulated by XBP1 in human monocytes. Sci Rep. 2015;5(1):8134. doi:10.1038/srep08134

29. Brown AJ, Goldsworthy SM, Barnes AA, et al. The Orphan G protein-coupled receptors GPR41 and GPR43 are activated by propionate and other short chain carboxylic acids. J Biol Chem. 2003;278(13):11312-11319. doi:10.1074/jbc.M211609200

30. Chang PV, Hao L, Offermanns S, Medzhitov R. The microbial metabolite butyrate regulates intestinal macrophage function via histone deacetylase inhibition. Proc Natl Acad Sci USA. 2014;111 (6):2247-2252. doi:10.1073/pnas.1322269111

31. Cox MA, Jackson J, Stanton M, et al. Short-chain fatty acids act as antiinflammatory mediators by regulating prostaglandin $\mathrm{E}(2)$ and cytokines. World J Gastroenterol. 2009;15(44):5549-5557. doi:10.3748/wjg.15.5549

32. Nastasi C, Candela M, Bonefeld CM, et al. The effect of short-chain fatty acids on human monocyte-derived dendritic cells. Sci Rep. 2015;5(1):16148. doi:10.1038/srep16148 
33. Singh N, Gurav A, Sivaprakasam S, et al. Activation of Gpr109a, receptor for niacin and the commensal metabolite butyrate, suppresses colonic inflammation and carcinogenesis. Immunity. 2014;40(1):128-139. doi:10.1016/j.immuni.2013.12.007

34. Thangaraju M, Cresci GA, Liu K, et al. GPR109A is a G-proteincoupled receptor for the bacterial fermentation product butyrate and functions as a tumor suppressor in colon. Cancer Res. 2009;69(7):2826-2832. doi:10.1158/0008-5472.CAN-08-4466

35. Tunaru S, Kero J, Schaub A, et al. PUMA-G and HM74 are receptors for nicotinic acid and mediate its anti-lipolytic effect. Nat Med. 2003;9(3):352-355. doi:10.1038/nm824

36. Kim MH, Kang SG, Park JH, Yanagisawa M, Kim CH. Short-chain fatty acids activate GPR41 and GPR43 on intestinal epithelial cells to promote inflammatory responses in mice. Gastroenterology. 2013;145(2):396-406 e391-310. doi:10.1053/j.gastro.2013.04.056

37. Bhatt B, Zeng $\mathrm{P}, \mathrm{Zhu} \mathrm{H}$, et al. Gpr109a limits microbiota-induced IL-23 production to constrain ILC3-mediated colonic inflammation. J Immunol. 2018;200(8):2905-2914. doi:10.4049/ jimmunol.1701625

38. Gong Y, Jin X, Yuan B, et al. G protein-coupled receptor 109A maintains the intestinal integrity and protects against ETEC mucosal infection by promoting IgA secretion. Front Immunol. 2020;11:583652. doi:10.3389/fimmu.2020.583652

39. Sivaprakasam S, Prasad PD, Singh N. Benefits of short-chain fatty acids and their receptors in inflammation and carcinogenesis. Pharmacol Ther. 2016;164:144-151. doi:10.10 16/j.pharmthera.2016.04.007

40. Mowat AM, Agace WW. Regional specialization within the intestinal immune system. Nat Rev Immunol. 2014;14:667-685.

41. Cresci GA, Bush K, Nagy LE. Tributyrin supplementation protects mice from acute ethanol-induced gut injury. Alcohol Clin Exp Res. 2014;38(6):1489-1501. doi:10.1111/acer.12428

42. Cresci GA, Glueck B, McMullen MR, Xin W, Allende D, Nagy LE. Prophylactic tributyrin treatment mitigates chronic-binge ethanol-induced intestinal barrier and liver injury. J Gastroenterol Hepatol. 2017;32(9):1587-1597. doi:10.1111/ jgh. 13731

43. Peng L, Li ZR, Green RS, Holzman IR, Lin J. Butyrate enhances the intestinal barrier by facilitating tight junction assembly via activation of AMP-activated protein kinase in Caco-2 cell monolayers. J Nutr. 2009;139(9):1619-1625. doi:10.3945/ jn.109.104638

44. Nielsen DSG, Jensen BB, Theil PK, Nielsen TS, Knudsen KEB, Purup S. Effect of butyrate and fermentation products on epithelial integrity in a mucus-secreting human colon cell line. J Funct Foods. 2018;40:9-17. doi:10.1016/j.jff.2017.10.023

45. Feng Y, Wang Y, Wang P, Huang Y, Wang F. Short-Chain Fatty Acids manifest stimulative and protective effects on intestinal barrier function through the inhibition of NLRP3 inflammasome and autophagy. Cell Physiol Biochem. 2018;49(1):190-205. doi:10.1159/000492853

46. Elamin EE, Masclee AA, Dekker J, Pieters HJ, Jonkers DM. Short-chain fatty acids activate AMP-activated protein kinase and ameliorate ethanol-induced intestinal barrier dysfunction in Caco-2 cell monolayers. J Nutr. 2013;143(12):1872-1881. doi:10.3945/jn.113.179549

47. Kelly CJ, Zheng L, Campbell EL, et al. Crosstalk between microbiota-derived Short-Chain Fatty Acids and intestinal epithelial HIF augments tissue barrier function. Cell Host Microbe. 2015;17(5):662-671. doi:10.1016/j.chom.2015.03.005

48. Peng L, He Z, Chen W, Holzman IR, Lin J. Effects of butyrate on intestinal barrier function in a Caco-2 cell monolayer model of intestinal barrier. Pediatr Res. 2007;61(1):37-41. doi:10.1203/01. pdr.0000250014.92242.f3
49. Bach knudsen KE, Lærke HN, Hedemann MS, et al. Impact of diet-modulated butyrate production on intestinal barrier function and inflammation. Nutrients. 2018;10(10):1499.

50. Burgueno JF, Abreu MT. Epithelial toll-like receptors and their role in gut homeostasis and disease. Nat Rev Gastroenterol Hepatol. 2020;17(5):263-278. doi:10.1038/s41575-019-0261-4

51. Elce A, Amato F, Zarrilli F, et al. Butyrate modulating effects on pro-inflammatory pathways in human intestinal epithelial cells. Benef Microbes. 2017;8(5):841-847. doi:10.3920/BM2016.0197

52. Andoh A, Bamba T, Sasaki M. Physiological and anti-inflammatory roles of dietary fiber and butyrate in intestinal functions. J Parenter Enteral Nutr. 1999;23(5_suppl):S70-S73. doi:10.1177/014860719902300518

53. Segain JP, Raingeard de la Bletiere D, Bourreille A, et al. Butyrate inhibits inflammatory responses through NFkappaB inhibition: implications for Crohn's disease. Gut. 2000;47 (3):397-403. doi:10.1136/gut.47.3.397

54. Song M, Xia B, Li J. Effects of topical treatment of sodium butyrate and 5-aminosalicylic acid on expression of trefoil factor 3 , interleukin 1beta, and nuclear factor kappaB in trinitrobenzene sulphonic acid induced colitis in rats. Postgrad Med J. 2006;82 (964):130-135. doi:10.1136/pgmj.2005.037945

55. Chen G, Ran X, Li B, et al. Sodium butyrate inhibits inflammation and maintains epithelium barrier integrity in a TNBS-induced inflammatory bowel disease mice model. EBioMedicine. 2018;30:317-325. doi:10.1016/j.ebiom.2018.03.030

56. Kinoshita M, Suzuki Y, Saito Y. Butyrate reduces colonic paracellular permeability by enhancing PPARgamma activation. Biochem Biophys Res Commun. 2002;293(2):827-831. doi:10.1016/S0006-291X(02)00294-2

57. Li M, van Esch B, Wagenaar GTM, Garssen J, Folkerts G, Henricks PAJ. Pro- and anti-inflammatory effects of short chain fatty acids on immune and endothelial cells. Eur J Pharmacol. 2018;831:52-59. doi:10.1016/j.ejphar.2018.05.003

58. Glueck B, Han Y, Cresci GAM. Tributyrin supplementation protects immune responses and vasculature and reduces oxidative stress in the proximal colon of mice exposed to chronic-binge ethanol feeding. J Immunol Res. 2018;2018:9671919. doi:10.1 155/2018/9671919

59. Zhao Y, Chen F, Wu W, et al. GPR43 mediates microbiota metabolite SCFA regulation of antimicrobial peptide expression in intestinal epithelial cells via activation of mTOR and STAT3. Mucosal Immunol. 2018;11(3):752-762. doi:10.1038/mi.201 7.118

60. Hase K, Eckmann L, Leopard JD, Varki N, Kagnoff MF. Cell differentiation is a key determinant of cathelicidin LL-37/human cationic antimicrobial protein 18 expression by human colon epithelium. Infect Immun. 2002;70(2):953-963. doi:10.1128/ IAI.70.2.953-963.2002

61. Schulthess J, Pandey S, Capitani M, et al. The Short Chain Fatty Acid butyrate imprints an antimicrobial program in macrophages. Immunity. 2019;50(2):432-445 e437. doi:10.1016/j.immuni.201 8.12.018

62. Vinolo MA, Rodrigues HG, Hatanaka E, Sato FT, Sampaio SC, Curi R. Suppressive effect of short-chain fatty acids on production of proinflammatory mediators by neutrophils. $J$ Nutr Biochem. 2011;22(9):849-855. doi:10.1016/j.jnutbio.2010.07.009

63. Sina C, Gavrilova O, Förster M, et al. G protein-coupled receptor 43 is essential for neutrophil recruitment during intestinal inflammation. J Immunol. 2009;183(11):7514-7522. doi:10.4049 /jimmunol.0900063

64. Vinolo MA, Ferguson GJ, Kulkarni S, et al. SCFAs induce mouse neutrophil chemotaxis through the GPR43 receptor. PLoS One. 2011;6(6):e21205. doi:10.1371/journal.pone.0021205 
65. Rodrigues HG, Takeo sato F, Curi R, Vinolo MAR. Fatty acids as modulators of neutrophil recruitment, function and survival. Eur J Pharmacol. 2016;785:50-58.

66. Aoyama M, Kotani J, Usami M. Butyrate and propionate induced activated or non-activated neutrophil apoptosis via HDAC inhibitor activity but without activating GPR-41/GPR-43 pathways. Nutrition. 2010;26(6):653-661. doi:10.1016/j.nut.2009.07.006

67. Mirmonsef P, Zariffard MR, Gilbert D, Makinde H, Landay AL, Spear GT. Short-chain fatty acids induce pro-inflammatory cytokine production alone and in combination with toll-like receptor ligands. Am J Reprod Immunol. 2012;67(5):391-400. doi:10.1111/j.1600-0897.2011.01089.x

68. Bailón E, Cueto-Sola M, Utrilla $\mathrm{P}$, et al. Butyrate in vitro immune-modulatory effects might be mediated through a proliferation-related induction of apoptosis. Immunobiology. 2010;215(11):863-873. doi:10.1016/j.imbio.2010.01.001

69. Kraneveld AD, Sagar S, Garssen J, Folkerts G. The two faces of mast cells in food allergy and allergic asthma: the possible concept of Yin Yang. Biochim Biophys Acta Mol Basis Dis. 2012;1822(1):93-99. doi:10.1016/j.bbadis.2011.06.013

70. Bischoff SC. Mast cells in gastrointestinal disorders. Eur J Pharmacol. 2016;778:139-145. doi:10.1016/j.ejphar.2016.02.018

71. Bischoff SC, Wedemeyer J, Herrmann A, et al. Quantitative assessment of intestinal eosinophils and mast cells in inflammatory bowel disease. Histopathology. 1996;28(1):1-13. doi:10.1046/j.1365-2559.1996.262309.x

72. Gelbmann CM, Mestermann S, Gross V, Kollinger M, Scholmerich J, Falk W. Strictures in Crohn's disease are characterised by an accumulation of mast cells colocalised with laminin but not with fibronectin or vitronectin. Gut. 1999;45(2):210-217. doi:10.1136/gut.45.2.210

73. Tan J, McKenzie C, Vuillermin PJ, et al. Dietary fiber and bacterial SCFA enhance oral tolerance and protect against food allergy through diverse cellular pathways. Cell Rep. 2016;15 (12):2809-2824. doi:10.1016/j.celrep.2016.05.047

74. Hung TV, Suzuki T. Dietary fermentable fiber reduces intestinal barrier defects and inflammation in colitic mice. J Nutr. 2016;146 (10):1970-1979. doi:10.3945/jn.116.232538

75. Araki Y, Kanauchi O, Sugihara H, Fujiyama Y, Hattori T. Germinated barley foodstuff suppresses dextran sulfate experimental colitis in rats: the role of mast cells. Int $J$ Mol Med. 2007;19:257-262.

76. Kanauchi O, Mitsuyama K, Homma T, et al. Treatment of ulcerative colitis patients by long-term administration of germinated barley foodstuff: multi-center open trial. Int $J \mathrm{Mol}$ Med. 2003;12:701-704

77. Hanai H, Kanauchi O, Mitsuyama K, et al. Germinated barley foodstuff prolongs remission in patients with ulcerative colitis. Int J Mol Med. 2004;13:643-647.

78. Wang CC, Wu H, Lin FH, et al. Sodium butyrate enhances intestinal integrity, inhibits mast cell activation, inflammatory mediator production and JNK signaling pathway in weaned pigs. Innate Immun. 2018;24(1):40-46. doi:10.1177/1753425917741970

79. Diakos C, Prieschl EE, Saemann MD, et al. n-butyrate inhibits Jun $\mathrm{NH}(2)$-terminal kinase activation and cytokine transcription in mast cells. Biochem Biophys Res Commun. 2006;349 (2):863-868. doi:10.1016/j.bbrc.2006.08.117

80. Artis D, Spits H. The biology of innate lymphoid cells. Nature. 2015;517(7534):293-301. doi:10.1038/nature14189

81. Cella M, Fuchs A, Vermi W, et al. A human natural killer cell subset provides an innate source of IL-22 for mucosal immunity. Nature. 2009;457(7230):722-725. doi:10.1038/nature07537

82. Kim SH, Cho BH, Kiyono H, Jang YS. Microbiota-derived butyrate suppresses group 3 innate lymphoid cells in terminal ileal Peyer's patches. Sci Rep. 2017;7(1):3980. doi:10.1038/s41598017-02729-6
83. Yang W, Yu T, Huang $\mathrm{X}$, et al. Intestinal microbiota-derived short-chain fatty acids regulation of immune cell IL-22 production and gut immunity. Nat Commun. 2020;11(1):4457. doi:10.1038/s41467-020-18262-6

84. Zenewicz LA. IL-22: there is a gap in our knowledge. Immunohorizons. 2018;2(6):198-207. doi:10.4049/immunoh orizons. 1800006

85. Ouyang W, O'Garra A. IL-10 family cytokines IL-10 and IL-22: from basic science to clinical translation. Immunity. 2019;50:871-891.

86. Millard AL, Mertes PM, Ittelet D, Villard F, Jeannesson P, Bernard J. Butyrate affects differentiation, maturation and function of human monocyte-derived dendritic cells and macrophages. Clin Exp Immunol. 2002;130(2):245-255. doi:10.1046/j.00099104.2002.01977.x

87. Gurav A, Sivaprakasam S, Bhutia YD, Boettger T, Singh N, Ganapathy V. Slc5a8, a Na+-coupled high-affinity transporter for short-chain fatty acids, is a conditional tumour suppressor in colon that protects against colitis and colon cancer under low-fibre dietary conditions. Biochem J. 2015;469(2):267-278. doi:10.1042/BJ20150242

88. Nastasi C, Fredholm S, Willerslev-Olsen A, et al. Butyrate and propionate inhibit antigen-specific $\mathrm{CD} 8+\mathrm{T}$ cell activation by suppressing IL-12 production by antigen-presenting cells. Sci Rep. 2017;7(1):14516. doi:10.1038/s41598-017-15099-w

89. Arpaia N, Campbell C, Fan X, et al. Metabolites produced by commensal bacteria promote peripheral regulatory T-cell generation. Nature. 2013;504(7480):451-455. doi:10.1038/ nature 12726

90. Correa-Oliveira R, Fachi JL, Vieira A, Sato FT, Vinolo MA. Regulation of immune cell function by short-chain fatty acids. Clin Transl Immunol. 2016;5(4):e73. doi:10.1038/cti.2016.17

91. Steinman RM. Linking innate to adaptive immunity through dendritic cells. Novartis Found Symp. 2006;279:101-109;discussion 109-113, 216-109.

92. Nam JH, Lee JH, Choi SY, et al. Functional ambivalence of dendritic cells: tolerogenicity and immunogenicity. Int $\mathrm{J} \mathrm{Mol}$ Sci. 2021;22(9):4430.

93. Kaisar MMM, Pelgrom LR, van der Ham AJ, Yazdanbakhsh M, Everts B. butyrate conditions human dendritic cells to prime type 1 regulatory $\mathrm{T}$ cells via both histone deacetylase inhibition and $\mathrm{G}$ protein-coupled receptor $109 \mathrm{~A}$ signaling. Front Immunol. 2017;8:1429. doi:10.3389/fimmu.2017.01429

94. Furusawa Y, Obata Y, Fukuda S, et al. Commensal microbe-derived butyrate induces the differentiation of colonic regulatory T cells. Nature. 2013;504(7480):446-450. doi:10.10 38/nature 12721

95. Kespohl M, Vachharajani N, Luu M, et al. The microbial metabolite butyrate induces expression of Th1-associated factors in CD4(+) T cells. Front Immunol. 2017;8:1036. doi:10.3389/ fimmu.2017.01036

96. Luu M, Weigand K, Wedi F, et al. Regulation of the effector function of CD8+ T cells by gut microbiota-derived metabolite butyrate. Sci Rep. 2018;8(1):14430. doi:10.1038/s41598-01832860-x

97. Trompette A, Gollwitzer ES, Pattaroni C, et al. Dietary fiber confers protection against flu by shaping Ly6c(-) patrolling monocyte hematopoiesis and $\mathrm{CD} 8(+) \mathrm{T}$ cell metabolism. Immunity. 2018;48(5):992-1005 e1008. doi:10.1016/j.immuni.2018.04.022

98. Bachem A, Makhlouf C, Binger KJ, et al. Microbiota-derived short-chain fatty acids promote the memory potential of antigen-activated CD8(+) T cells. Immunity. 2019;51(2):285-297 e285. doi:10.1016/j.immuni.2019.06.002

99. Ji L, Hu X. Sweet memories of 8 empowered by butyrate. Immunity. 2019;51(2):201-203. doi:10.1016/j.immuni.2019.0 7.005 
100. Sun $\mathrm{M}, \mathrm{Wu} \mathrm{W}, \mathrm{Chen} \mathrm{L}$, et al. Microbiota-derived short-chain fatty acids promote Th1 cell IL-10 production to maintain intestinal homeostasis. Nat Commun. 2018;9(1):3555. doi:10.1038/s41467018-05901-2

101. Kim DS, Woo JS, Min HK, et al. Short-chain fatty acid butyrate induces IL-10-producing B cells by regulating circadian-clockrelated genes to ameliorate Sjogren's syndrome. J Autoimmun. 2021;119:102611. doi:10.1016/j.jaut.2021.102611

102. Rosser EC, Piper CJM, Matei DE, et al. Microbiota-derived metabolites suppress arthritis by amplifying aryl-hydrocarbon receptor activation in regulatory B cells. Cell Metab. 2020;31 (4):837-851 e810. doi:10.1016/j.cmet.2020.03.003

103. Daien CI, Tan J, Audo R, et al. Gut-derived acetate promotes B10 cells with antiinflammatory effects. JCI Insight. 2021;6(7). doi:10.1172/jci.insight.144156.

104. Sanchez HN, Moroney JB, Gan H, et al. B cell-intrinsic epigenetic modulation of antibody responses by dietary fiber-derived short-chain fatty acids. Nat Commun. 2020;11(1):60. doi:10.1038/ s41467-019-13603-6

105. Kim M, Qie Y, Park J, Kim CH. Gut microbial metabolites fuel host antibody responses. Cell Host Microbe. 2016;20(2):202-214. doi:10.1016/j.chom.2016.07.001

106. Chang JT. Pathophysiology of inflammatory bowel diseases. $N$ Engl J Med. 2020;383(27):2652-2664. doi:10.1056/NEJMra2002697

107. Takahashi K, Nishida A, Fujimoto T, et al. Reduced abundance of butyrate-producing bacteria species in the Fecal microbial community in Crohn's disease. Digestion. 2016;93(1):59-65. doi:10.1159/ 000441768

108. Machiels K, Joossens M, Sabino J, et al. A decrease of the butyrate-producing species Roseburia hominis and Faecalibacterium prausnitzii defines dysbiosis in patients with ulcerative colitis. Gut. 2014;63(8):1275-1283. doi:10.1136/gutjnl-2013-304833

109. Sauer J, Richter KK, Pool-Zobel BL. Physiological concentrations of butyrate favorably modulate genes of oxidative and metabolic stress in primary human colon cells. J Nutr Biochem. 2007;18(11):736-745. doi:10.1016/j.jnutbio.2006.12.012

110. Silva JPB, Navegantes-Lima KC, Oliveira ALB, et al. Protective mechanisms of butyrate on inflammatory bowel disease. Curr Pharm Des. 2018;24(35):4154-4166. doi:10.2174/138161 2824666181001153605

111. Roediger WE. The colonic epithelium in ulcerative colitis: an energy-deficiency disease? Lancet. 1980;2(8197):712-715. doi:10.1016/S0140-6736(80)91934-0

112. Singh B, Halestrap AP, Paraskeva C. Butyrate can act as a stimulator of growth or inducer of apoptosis in human colonic epithelial cell lines depending on the presence of alternative energy sources. Carcinogenesis. 1997;18(6):1265-1270. doi:10.1093/carcin/ 18.6.1265

113. Rosignoli P, Fabiani R, De Bartolomeo A, et al. Protective activity of butyrate on hydrogen peroxide-induced DNA damage in isolated human colonocytes and HT29 tumour cells. Carcinogenesis. 2001;22(10):1675-1680. doi:10.1093/carcin/22.10.1675

114. Abrahamse SL, Pool-Zobel BL, Rechkemmer G. Potential of short chain fatty acids to modulate the induction of DNA damage and changes in the intracellular calcium concentration by oxidative stress in isolated rat distal colon cells. Carcinogenesis. 1999;20(4):629-634. doi:10.1093/carcin/20.4.629

115. Barclay AR, Russell RK, Wilson ML, Gilmour WH, Satsangi J, Wilson DC. Systematic review: the role of breastfeeding in the development of pediatric inflammatory bowel disease. J Pediatr. 2009;155(3):421-426. doi:10.1016/j.jpeds.2009.03.017

116. Gao Y, Davis B, Zhu W, Zheng N, Meng D, Walker WA. Shortchain fatty acid butyrate, a breast milk metabolite, enhances immature intestinal barrier function genes in response to inflammation in vitro and in vivo. Am J Physiol Gastrointest Liver Physiol. 2021;320(4):G521-G530. doi:10.1152/ajpgi.00279.2020
117. Guo H, Callaway JB, Ting JPY. Inflammasomes: mechanism of action, role in disease, and therapeutics. Nat Med. 2015;21 (7):677-687. doi:10.1038/nm.3893

118. Zhen Y, Zhang H. NLRP3 inflammasome and inflammatory bowel disease. Front Immunol. 2019;10:276. doi:10.3389/ fimmu.2019.00276

119. Luzardo-Ocampo I, Loarca-Pina G, Gonzalez de Mejia E. Gallic and butyric acids modulated NLRP3 inflammasome markers in a co-culture model of intestinal inflammation. Food Chem Toxicol. 2020;146:111835. doi:10.1016/j.fct.2020.111835

120. Bocker U, Nebe T, Herweck F, et al. Butyrate modulates intestinal epithelial cell-mediated neutrophil migration. Clin Exp Immunol. 2003;131(1):53-60. doi:10.1046/j.1365-2249.2003.02056.x

121. Chen J, Vitetta L. Butyrate in inflammatory bowel disease therapy. Gastroenterology. 2020;158(5):1511. doi:10.1053/j. gastro.2019.08.064

122. Geirnaert A, Calatayud M, Grootaert C, et al. Butyrate-producing bacteria supplemented in vitro to Crohn's disease patient microbiota increased butyrate production and enhanced intestinal epithelial barrier integrity. Sci Rep. 2017;7(1):11450. doi:10.1038/s41598-017-11734-8

123. Luzardo-Ocampo I, Campos-Vega R, Gonzalez de Mejia E, Loarca-Piña G. Consumption of a baked corn and bean snack reduced chronic colitis inflammation in CD-1 mice via downregulation of IL-1 receptor, TLR, and TNF- $\alpha$ associated pathways. Food Res Int. 2020;132:109097. doi:10.1016/j. foodres.2020.109097

124. Smith PM, Howitt MR, Panikov N, et al. The microbial metabolites, short-chain fatty acids, regulate colonic $\mathrm{T}$ reg cell homeostasis. Science. 2013;341(6145):569-573. doi:10.1126/ science. 1241165

125. Zhang M, Zhou Q, Dorfman RG, et al. Butyrate inhibits interleukin-17 and generates Tregs to ameliorate colorectal colitis in rats. BMC Gastroenterol. 2016;16(1):84. doi:10.1186/s12876016-0500-x

126. Venkatraman A, Ramakrishna BS, Pulimood AB, Patra S, Murthy S. Increased permeability in dextran sulphate colitis in rats: time course of development and effect of butyrate. Scand $J$ Gastroenterol. 2000;35(10):1053-1059. doi:10.1080/003655200451171

127. Zhang T, Ding C, Zhao M, et al. Sodium butyrate reduces colitogenic immunoglobulin A-coated bacteria and modifies the composition of microbiota in IL-10 deficient mice. Nutrients. 2016;8 (12):728. doi:10.3390/nu8120728

128. Butzner JD, Parmar R, Bell CJ, Dalal V. Butyrate enema therapy stimulates mucosal repair in experimental colitis in the rat. Gut. 1996;38(4):568-573. doi:10.1136/gut.38.4.568

129. Bloemen JG, Schreinemacher MH, de Bruine AP, Buurman WA, Bouvy ND, Dejong $\mathrm{CH}$. Butyrate enemas improve intestinal anastomotic strength in a rat model. Dis Colon Rectum. 2010;53 (7):1069-1075. doi:10.1007/DCR.0b013e3181d881b7

130. Mishiro T, Kusunoki R, Otani A, et al. Butyric acid attenuates intestinal inflammation in murine DSS-induced colitis model via milk fat globule-EGF factor 8. Lab Investig. 2013;93(7):834-843. doi:10.1038/labinvest.2013.70

131. Burrello C, Giuffre MR, Macandog AD, et al. Fecal microbiota transplantation controls murine chronic intestinal inflammation by modulating immune cell functions and gut microbiota composition. Cells. 2019;8(6):517. doi:10.3390/cells8060517

132. Wen X, Wang HG, Zhang MN, Zhang MH, Wang H, Yang XZ. Fecal microbiota transplantation ameliorates experimental colitis via gut microbiota and T-cell modulation. World J Gastroenterol. 2021;27(21):2834-2849. doi:10.3748/wjg.v27.i21.2834

133. Scheppach W, Sommer H, Kirchner T, et al. Effect of butyrate enemas on the colonic mucosa in distal ulcerative colitis. Gastroenterology. 1992;103(1):51-56. doi:10.1016/00165085(92)91094-K 
134. Steinhart AH, Hiruki T, Brzezinski A, Baker JP. Treatment of left-sided ulcerative colitis with butyrate enemas: a controlled trial. Aliment Pharmacol Ther. 1996;10(5):729-736. doi:10.1046/j.1365-2036.1996.d01-509.x

135. Breuer RI, Soergel KH, Ba L, et al. Short chain fatty acid rectal irrigation for left-sided ulcerative colitis: a randomised, placebo controlled trial. Gut. 1997;40(4):485-491. doi:10.1136/ gut.40.4.485

136. Hamer HM, Jonkers DM, Vanhoutvin SA, et al. Effect of butyrate enemas on inflammation and antioxidant status in the colonic mucosa of patients with ulcerative colitis in remission. Clin Nutr. 2010;29(6):738-744. doi:10.1016/j.clnu.2010.04.002

137. Jamka M, Kokot M, Kaczmarek N, Bermagambetova S, Nowak JK, Walkowiak J. The effect of sodium butyrate enemas compared with placebo on disease activity, endoscopic scores, and histological and inflammatory parameters in inflammatory bowel diseases: a systematic review of randomised controlled trials. Complement Med Res. 2020;28(4):1-13.

138. Vernero M, De Blasio F, Ribaldone DG, et al. The usefulness of microencapsulated sodium butyrate add-on therapy in maintaining remission in patients with ulcerative colitis: a prospective observational study. J Clin Med. 2020;9(12):3941. doi:10.3390/jcm9123941

139. Tominaga K, Kamimura K, Takahashi K, Yokoyama J, Yamagiwa S, Terai S. Diversion colitis and pouchitis: a mini-review. World J Gastroenterol. 2018;24(16):1734-1747. doi:10.3748/wjg.v24.i16.1734

140. Luceri C, Femia AP, Fazi M, et al. Effect of butyrate enemas on gene expression profiles and endoscopic/histopathological scores of diverted colorectal mucosa: a randomized trial. Dig Liver Dis. 2016;48(1):27-33. doi:10.1016/j.dld.2015.09.005

141. Rubin DT, Ananthakrishnan AN, Siegel CA, Sauer BG, Long MD. ACG clinical guideline: ulcerative colitis in adults. Am J Gastroenterol. 2019;114:384-413.

142. Bischoff SC, Escher J, Hébuterne X, et al. ESPEN practical guideline: clinical nutrition in inflammatory bowel disease. Clin Nutr. 2020;39(3):632-653. doi:10.1016/j.clnu.2019.11.002

143. Akutko K, Stawarski A. Probiotics, prebiotics and synbiotics in inflammatory bowel diseases. J Clin Med. 2021;10(11):2466. doi: $10.3390 / \mathrm{jcm} 10112466$

144. Fehily SR, Basnayake C, Wright EK, Kamm MA. Fecal microbiota transplantation therapy in Crohn's disease: systematic review. J Gastroenterol Hepatol. 2021;36(10):2672-2686. doi:10.1111/jgh. 15598

145. Imdad A, Nicholson MR, Tanner-Smith EE, et al. Fecal transplantation for treatment of inflammatory bowel disease. Cochrane Database Syst Rev. 2018;11:Cd012774.

146. Narula N, Kassam Z, Yuan Y, et al. Systematic review and meta-analysis: fecal microbiota transplantation for treatment of active ulcerative colitis. Inflamm Bowel Dis. 2017;23 (10):1702-1709. doi:10.1097/MIB.0000000000001228

147. Yusuf F, Adewiah S, Fatchiyah F. The level short chain fatty acids and HSP 70 in colorectal cancer and non-colorectal cancer. Acta Inform Med. 2018;26(2):160-163. doi:10.5455/aim.2018.26.160-163

148. Sengupta S, Muir JG, Gibson PR. Does butyrate protect from colorectal cancer? J Gastroenterol Hepatol. 2006;21(1):209-218. doi:10.1111/j.1440-1746.2006.04213.x
149. D’Argenio G, Cosenza V, Delle Cave M, et al. Butyrate enemas in experimental colitis and protection against large bowel cancer in a rat model. Gastroenterology. 1996;110(6):1727-1734. doi:10.1053/gast.1996.v110.pm8964397

150. Hague A, Manning AM, Hanlon KA, Huschtscha LI, Hart D, Paraskeva C. Sodium butyrate induces apoptosis in human colonic tumour cell lines in a p53-independent pathway: implications for the possible role of dietary fibre in the prevention of large-bowel cancer. Int $J$ Cancer. 1993;55(3):498-505. doi:10.1002/ijc.2910550329

151. Yu DCW, Waby JS, Chirakkal H, Staton CA, Corfe BM. Butyrate suppresses expression of neuropilin I in colorectal cell lines through inhibition of Sp1 transactivation. Mol Cancer. 2010;9 (1):276. doi:10.1186/1476-4598-9-276

152. Zuo L, Lu M, Zhou Q, Wei W, Wang Y. Butyrate suppresses proliferation and migration of RKO colon cancer cells though regulating endocan expression by MAPK signaling pathway. Food Chem Toxicol. 2013;62:892-900. doi:10.1016/j.fct.2013.10.028

153. Lazarova DL, Chiaro C, Bordonaro M. Butyrate induced changes in Wnt-signaling specific gene expression in colorectal cancer cells. BMC Res Notes. 2014;7(1):226. doi:10.1186/1756-0500-7-226

154. Nusse R, Clevers H. Wnt/ $\beta$-catenin signaling, disease, and emerging therapeutic modalities. Cell. 2017;169(6):985-999. doi:10.1016/j.cell.2017.05.016

155. Han R, Sun Q, Wu J, Zheng P, Zhao G. Sodium butyrate upregulates miR-203 expression to exert anti-proliferation effect on colorectal cancer cells. Cell Physiol Biochem. 2016;39 (5):1919-1929. doi:10.1159/000447889

156. Hu S, Liu L, Chang EB, Wang JY, Raufman JP. Butyrate inhibits pro-proliferative miR-92a by diminishing c-Myc-induced miR-17-92a cluster transcription in human colon cancer cells. Mol Cancer. 2015;14(1):180. doi:10.1186/s12943-015-0450-x

157. Song M, Wu K, Meyerhardt JA, et al. Fiber intake and survival after colorectal cancer diagnosis. JAMA Oncol. 2018;4(1):71-79. doi:10.1001/jamaoncol.2017.3684

158. Alberts DS, Ritenbaugh C, Story JA, et al. Randomized, double-blinded, placebo-controlled study of effect of wheat bran fiber and calcium on fecal bile acids in patients with resected adenomatous colon polyps. J Natl Cancer Inst. 1996;88(2):81-92. doi:10.1093/jnci/88.2.81

159. Papadimitriou N, Markozannes G, Kanellopoulou A, et al. An umbrella review of the evidence associating diet and cancer risk at 11 anatomical sites. Nat Commun. 2021;12(1):4579. doi:10.1038/s41467-021-24861-8

160. Veettil SK, Wong TY, Loo YS, et al. Role of diet in colorectal cancer incidence: umbrella review of meta-analyses of prospective observational studies. JAMA Netw Open. 2021;4(2): e2037341-e2037341. doi:10.1001/jamanetworkopen.2020.37341

161. Kim YI. AGA technical review: impact of dietary fiber on colon cancer occurrence. Gastroenterology. 2000;118(6):1235-1257. doi:10.1016/S0016-5085(00)70377-5

162. Hajjar R, Richard CS, Santos MM. The role of butyrate in surgical and oncological outcomes in colorectal cancer. Am J Physiol Gastrointest Liver Physiol. 2021;320(4):G601-G608. doi:10.1152/ajpgi.00316.2020

163. Cleveland Clinic Center for Medical Art and Photography. Available from: https://my.clevelandclinic.org/ 


\section{Publish your work in this journal}

The Journal of Inflammation Research is an international, peerreviewed open-access journal that welcomes laboratory and clinical findings on the molecular basis, cell biology and pharmacology of inflammation including original research, reviews, symposium reports, hypothesis formation and commentaries on: acute/chronic inflammation; mediators of inflammation; cellular processes; molecular mechanisms; pharmacology and novel anti-inflammatory drugs; clinical conditions involving inflammation. The manuscript management system is completely online and includes a very quick and fair peerreview system. Visit http://www.dovepress.com/testimonials.php to read real quotes from published authors. 